South African Journal of Geomatics, Vol. 4, No. 1, February 2015

\title{
Estimation and mapping of above ground biomass and carbon of Bwindi impenetrable National Park using ALOS PALSAR data
}

\author{
John Richard Otukei ${ }^{1}$, Male Emanuel ${ }^{1}$ \\ ${ }^{1}$ Department of Geomatics and Land Management, Makerere University, P.O. Box 7062 Kampala- \\ Uganda, Email: jrotukei@ cedat.mak.ac.ug
}

DOI: http://dx.doi.org/10.4314/sajg.v4i1.1

\begin{abstract}
:
Biomass is an important parameter for bioenergy modelling, food security, environmental assessment and climate change research. However, estimation of biomass is still a challenging task especially in areas with complex forest stand structures and environmental conditions. The aim of this research was to estimate the Above Ground Biomass (AGB) and carbon stocks in the Bwindi Impenetrable National Park (BINP) using the Horizontal-Horizontal (HH) and Horizontal-Vertical (HV) polarizations acquired by the L-band ALOS PALSAR instrument. In addition, field data from 35 sample plots comprising of the Diameter at Breast Height (DBH), co-ordinates of centroids and angles to the top and bottom of the individual trees was used for the analysis. The relationship between biomass and radar backscatter for selected sample plots was established using pairwise correlation. A strong correlation between the radar backscatter and AGB was found using the HV polarization compared with the HH polarization. Overall, ALOS PALSAR data has a strong potential for biomass and carbon estimation in the tropical areas such as the BINP.
\end{abstract}

\section{Introduction}

Biomass is an important variable for bioenergy modeling, food security, environmental assessment and climate change research. It comprises of both the below and above ground living mass or organic material including: roots, shrubs, vines, crops, tree litter and dead mass associated with soil (Amado, 2012). Forests are of great ecological and economic importance and are a source of timber, fire wood, herbal medicines, and food. Additionally, forests play a significant role in the carbon cycle. On one hand forests act as carbon emitters during degradation and deforestation. In this way, forest loss results in a direct increase in carbon dioxide $\left(\mathrm{CO}_{2}\right)$, a greenhouse gas responsible for global warming. On the other hand, trees absorb $\mathrm{CO}_{2}$ during photosynthesis resulting in a decrease in the carbon amounts in the atmosphere. 
The global forests assessment report published in 2010 shows that the world's forests store an estimated amount of 289 Gigatonnes of carbon in their biomass alone (FAO, 2010). Furthermore, the report highlighted that 5.2 million hectares of tropical forest land were lost per year between 2000 and 2010, with the highest deforestation rates reported in Africa and South America. It is projected that if the forest loss continues at this rate, there will be nearly no tropical rainforest remaining by 2035 . The post -Kyoto climate change agreement on reducing emissions from deforestation and degradation (REDD) is an attempt to mitigate the rising $\mathrm{CO}_{2}$ levels in the atmosphere. The aim of these scheme is to reduce the rate of deforestation and degradation via performance related payments (Clements, 2010).

Spatially explicit maps showing the above ground biomass are essential for calculating the losses and gains in forest carbon at regional and national levels (Hill et al., 2013, Mitchard et al., 2011). However, assessment of biomass is a challenging task especially in areas with complex forest stand structures and environmental conditions ( $\mathrm{Lu}, 2006)$. As a result, the carbon estimates from deforestation and forest degradation at local, national and global scales are poorly unknown. Traditional methods based on field measurements, although able to provide accurate results are laborious, time consuming and difficult to extend beyond the local scale of analysis. Additionally these methods cannot provide spatially explicit distribution of forest biomass.

Over the years, remote sensing has become an attractive data source for biomass estimation and assessment. Remote sensing provides repetitive data collection, a synoptic view and high correlation between spectral bands and vegetation parameters making it suitable for biomass estimation. Several studies have been conducted demonstrating the potential of passive and active remote sensing for biomass studies (Anaya et al., 2009, Austin et al., 2003, Powell et al., 2010, Lucas et al., 2010, Gonzalez et al., 2010, Luckman et al., 1997, Amado, 2012, Mitchard et al., 2011, Ranson and Sun, 1994, Rauste, 2005, Kuplich, 2000, De Jong, 2003, Santos, 2003, Sun, 2002, Thenkabail, 2004). However, despite all these efforts, there is no universally accepted method for estimating the above ground biomass estimation (Mitchard et al., 2009, Powell et al., 2010). While medium resolution satellite images, notably data from the Landsat sensors has been the commonest for forest biomass estimation (Powell et al., 2010), the persistent cloud cover in the tropical regions makes acquisition of quality optical remote sensing data difficult. Also, methods used for biomass estimation based on optical imagery involve the assessment of correlation between spectral response and biomass. Since the spectral response depends on the sun's radiation and forest stand canopy, the correlation between biomass and spectral response is always poor especially for mature forest leading to saturation (Mitchard et al., 2011, Naiseh et al., 2010). 
Imaging radar systems illuminate surface features like vegetation, buildings and water bodies with microwave energy and record the returned signal. Biomass is the component in vegetation that mostly reflects the radar rays that are recorded by the active sensors. This means a relationship exists between biomass and radar backscatter. Overall, higher biomass forests exhibit higher backscatter reflectance while lower biomass forests reflect less backscatter. Radar remote sensing is not very much affected by weather conditions and as such provides potential for biomass assessment especially in the tropical regions with persistent cloud cover.

However, the success of radar remote sensing for biomass and carbon assessment depends on the choice of the radar bands and polarization. Some of the commonly used radar bands are the X-, C-, Land P-bands. The X-and P- bands are characterised by short and long wavelength radiations leading to the low and high penetration power respectively. In the case of forest applications, the X-band radiations are easily scattered by the leaves of trees while the P-band radiations can reach the bottom of the tree canopy. Both the X-and C- bands saturate at lower biomass amounts compared to L- and P-bands. Each radar signal can be propagated to and received from objects of interest in the Horizontal $(\mathrm{H})$ or Vertical (V) polarizations resulting in $\mathrm{HH}, \mathrm{VV}, \mathrm{HV}$ and $\mathrm{VH}$ possible polarimetric combinations. The cross polarizations $\mathrm{HV}$ and $\mathrm{VH}$ caused by multiple scattering have the most sensitivity to biomass and are less influenced by surface conditions (Ranson and Sun, 1994). In addition to the radar bands and polarization, the nature of terrain can also affect the amounts of biomass and carbon estimated from radar data. Hilly and ragged terrain leads to layover, foreshortening and shadowing which affects the quality of radar data leading to poor estimates biomass and carbon.

Biomass estimation from radar data can be achieved using either the Synthetic Aperture Radar (SAR) backscatter values or Polarimetric Synthetic Aperture Radar Interferometry (PolInSAR). The most common method involves relating the biomass amounts with SAR backscatter values. Depending on the landscape characteristics, this method provides good results (Austin et al., 2003, Beaudoin, 1994). However, this approach is affected by saturation levels which are dependent upon the radar wavelength and polarization. An alternative involves the use of SAR interferometry which requires analysis of the phase between two images acquired at the same time by two identical instruments or images acquired by the same instrument over a period of time. However, this method is affected by the site conditions such as the wind speed, direction and moisture (Pulliainen, 2003).

The aim of this study was to provide biomass and carbon estimates in BINP using the L-band ALOS PALSAR and ground data. While some successes have been reported in using radar data for biomass 
assessment (Austin et al., 2003, Pulliainen, 2003), most of these studies have been conducted in areas with homogenous forest cover types with less forest stand structures. The feasibility of ALOS PALSAR for biomass estimation in complex tropical environments such as BINP with mixed forest cover types and undulating terrain is still not well known.

\section{Study area}

The study area is the BINP located in the south-western part of Uganda cutting across the districts of Kabale, Rukungiri, Kisoro and Kanungu (see Figure 1). It is bounded by latitudes ( $\left(0^{0} 53^{\prime}-1^{0} 08^{\prime}\right) \mathrm{S}$ and longitudes $\left(29^{0} 35^{\prime}-29^{0} 50^{\prime}\right) \mathrm{E}$, with an estimated area of 331 square kilometers. The BINP is part and parcel of the highest blocks of Kigezi and Rukiga highlands and lies at the edge of the great western rift valley. A small area of the park stretches to the east of the Democratic Republic of Congo.

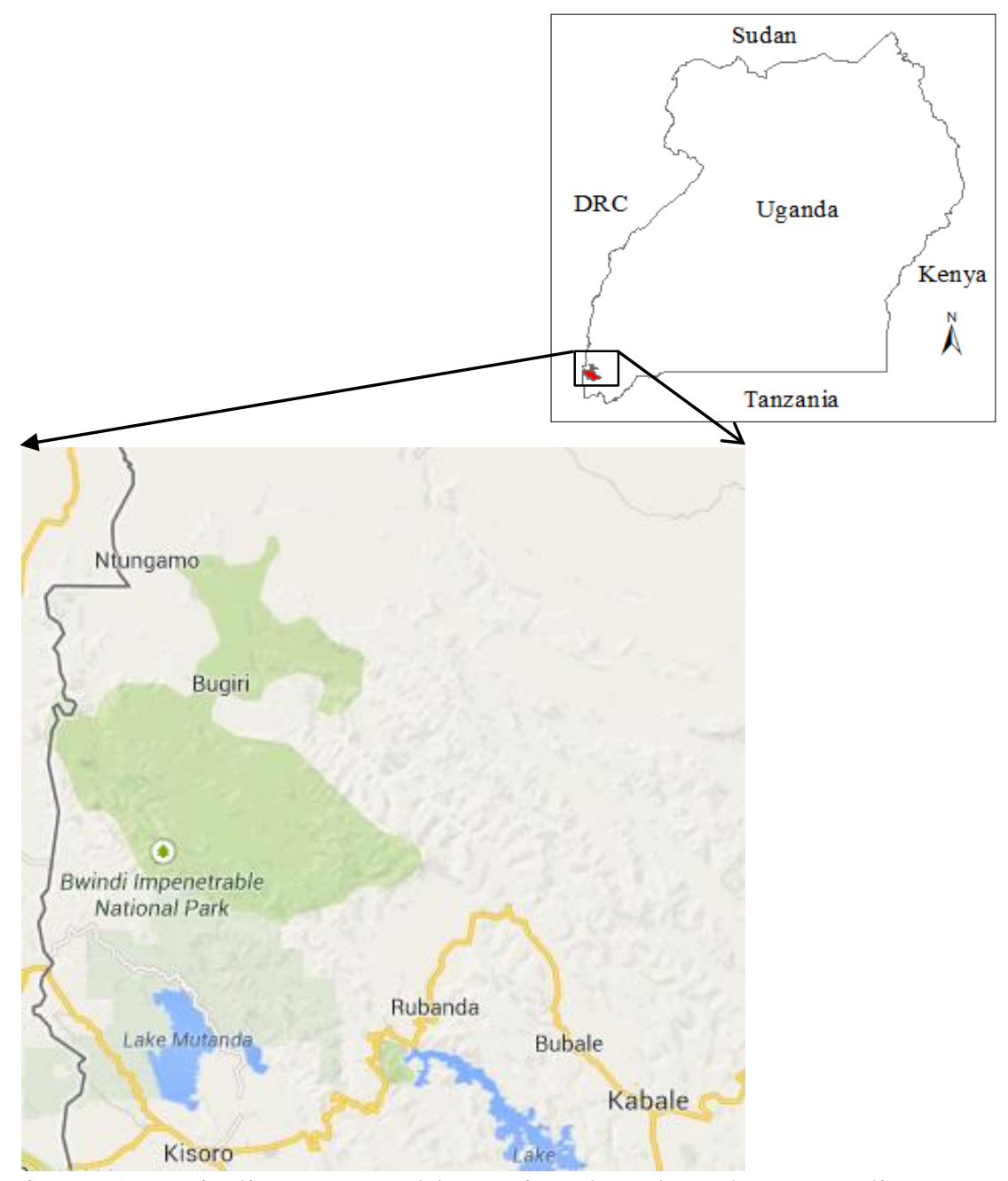

Figure 1. Bwindi Impenetrable National Park and surrounding areas 
The landscape is rugged and characterized by deep narrow valleys with steep sided hills. The altitude ranges from $1160 \mathrm{~m}$ (3805ft) at the top of the northern sector to $2607 \mathrm{~m}(8551 \mathrm{ft})$ at the Rwamunyonyi hill on the south-eastern edge of the park. Flat areas can only be found in the Mubwindi and Ngoto swamps. The BINP constitutes an important water catchment area, serving the surrounding agricultural lands. Three major tributaries of the Ishasha River drain into Lake Edward to the northern part of the park, while the Ndengo, Kanyamwabo and Shongi Rivers flow southwards towards Lake Mutanda and Lake Bunyonyi.

The Bwindi forest is characterized as an Afromontane forest which is considered the rarest vegetation type on the continent. Subsistence agriculture dominates the surrounding areas with bananas, potatoes and tea as the main cultivated crops. The climate is tropical with two rainfall peaks from March to May and September to November. There are two dry seasons from December to January and June to August. Annual precipitation lies in the range 1,130-2,390 $\mathrm{mm}$ with mean and maximum annual temperature ranges of $7-15^{\circ} \mathrm{C}$ and $20-27^{\circ} \mathrm{C}$ respectively.

The study area was selected because it is an important park for conservation in Uganda as well as a UNESCO world heritage site. Additionally, the terrain in BINP is undulating and rugged and presents a good test site for evaluating the performance ALOS PALSAR data for biomass study.

\section{Data and Methods}

\subsection{Data}

In this study, ALOS-PALSAR polarimetric data (level 1.5) with a spatial resolution of $12.5 \mathrm{~m} \mathrm{x}$ $12.5 \mathrm{~m}$ was used for biomass and carbon estimation. The data was acquired on May 3, 2005. Only the $\mathrm{HH}$ and HV polarizations were selected for the analysis. The ALOS PALSAR sensor is an L-band SAR instrument and is one of the three sensors carried on-board the ALOS satellite. The other sensors are the Panchromatic Remote-sensing Instrument Stereo Mapping (PRISM) and the advanced visible and near infrared radiometer type 2 (AVNIR-2). Field data collected using Global Positioning Systems (GPS) and Suunto instruments supplemented ALOS-PALSAR data for biomass estimation, modeling and validation. Stata software was used for statistical analysis, while Erdas Imagine was used to re-project the ALOS PALSAR image from Clarke 1886 to WGS84. ArcGIS was used for map preparation and visualization. 
There was a time lag of about 5 years between radar and field data collection. This was a limitation to the study since the only latest available ALOS PALSAR data was that acquired in 2005. However, while this time difference can affect the accuracies of the model and its predictions, we argue that the effect is minimal because the core boundary of the Bwindi national park has remained intact with less deforestation and degradation. Additionally, Bwindi forest is a natural tropical moist rain forest and it is expected that the vegetation cover does not change much in terms of species cover, $\mathrm{DBH}$ and height unless forests degradation has taken place.

\subsection{Sampling design and data collection}

A purposive sampling based on tree species composition, terrain orientation, topographic features, stand density and volume was adopted for collecting data in 35 circular plots (Figure 2). A radius of $15 \mathrm{~m}$ was selected in order to provide field plots that cover an area of at least one pixel of ALOS- PALSAR data.

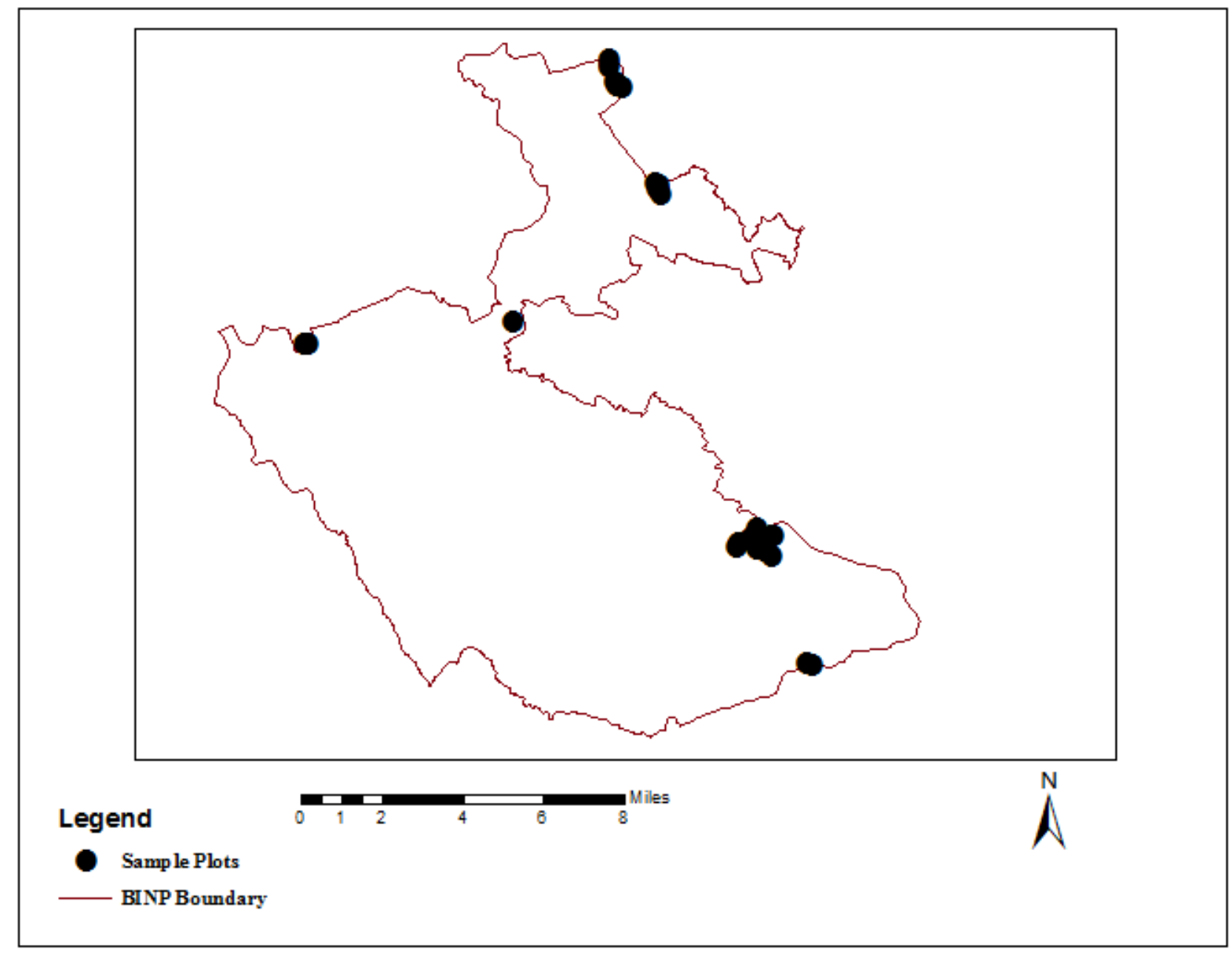

Figure 2. Location of field samples 
Trees with DBH of less than $10 \mathrm{~cm}$ were not considered for measurement as these contribute less to the total biomass content of forests (Brown, 2002). The DBH is the diameter of a tree at a height of $1.3 \mathrm{~m}$ from the ground and can be measured directly or indirectly using a caliper or a tape respectively. In each plot, the DBH, horizontal distances to a tree, angles to the top and bottom of trees and coordinates of centroids of plots were measured and used as inputs for biomass estimation.

\subsection{Estimation of biomass using measured tree parameters}

The estimation of biomass based on tree parameters measured from the field was done using an allometric equation developed for tropical forests (Chave et al., 2005) and formulated as:

$$
A G B=0.0509 \times \rho D^{2} H
$$

Where:

AGB is the above ground biomass, D is the diameter at breast height $(\mathrm{cm}), \mathrm{H}$ is the tree height $(\mathrm{m}), \rho$ is the wood specific gravity $\left(\mathrm{g} \mathrm{cm}^{3}\right)$ and estimated as 0.88 (ICIMOD et al., 2010). The tree height (H) was indirectly determined based on equation 2 .

$$
\begin{aligned}
& \text { Height }=\left[-\left((\operatorname{COS} \alpha) *\left(\operatorname{SQRT}\left(d^{\wedge} 2-((\operatorname{COS} \alpha) * 1.55) \wedge 2\right)-((\operatorname{SIN} \alpha) * 1.55)\right) *(\operatorname{TAN} \alpha)+(\operatorname{COS}\right.\right. \\
& \left.\alpha) *\left(\operatorname{SQRT}\left(d^{\wedge} 2-((\operatorname{COS} \alpha) * 1.55) \wedge 2\right)-((\operatorname{SIN} \alpha) * 1.55) * \operatorname{TAN} \beta\right)\right]
\end{aligned}
$$

Where: $\beta$ and $\alpha$ are angles in radians measured to the bottom and top of each tree while $d$ is the approximate horizontal distance to base of the tree.

\subsection{Regression analysis}

Regression analysis was carried out to determine the relationship between biomass estimated using field measured parameters and radar backscatter. The Digital Numbers (DNs) corresponding to each sampled plot were converted to radar backscatter coefficient using equation 3.

$$
\operatorname{NRCS}(\mathrm{dB})=10 * \log 10(\mathrm{DN})^{2}+\mathrm{CF}
$$

Where: NRCS is the normalised radar cross section (backscatter coefficient) measured in Decibels (dB), $\mathrm{CF}$ is the calibration factor $(-83 \mathrm{~dB})$ and $\mathrm{DN}$ is digital number. A linear regression model was used to establish the relationship between the average backscatter values of the $\mathrm{HH}$ and $\mathrm{HV}$ polarizations with estimated AGB. A multi-linear model shown in equation 4 was developed by combining the $\mathrm{HH}$ and $\mathrm{HV}$ backscatter values for estimation of the AGB. 


$$
B=a x_{1}+b x_{2}+c
$$

Where $\mathrm{a}=-55.39978, \mathrm{~b}=319.7536$ and $\mathrm{c}=77339.48$ are the free parameters, the independent variables $\mathrm{x}_{1}, \mathrm{x}_{2}$ are the average calibrated normalised backscatter values extracted from the $\mathrm{HH}$ and $\mathrm{HV}$ polarizations while the dependent term B is the estimated AGB. The performance of the derived model was evaluated by comparing the estimated biomass to the measured biomass of 10 independent plots. Foreshortening, layover and shadowing which are known problems of radar remote sensing affected some plots which were consequently excluded from the analysis. The model was then applied to convert backscatter values to biomass of the entire image. The resulting biomass estimates were converted to carbon stocks using the conversion factor of 0.5 (Chave et al., 2005) as shown in equation [5].

$$
\text { Carbon }=\mathrm{AGB} * 0.5
$$

\section{Results and Discussion}

\subsection{Variation of estimated biomass in the given plots}

Figure 3 shows the variation of estimated biomass a cross the sampled plots. The two tree parameters used for biomass estimation were the DBH and height. A total of 592 trees were measured with average height and DBH of $19.738 \mathrm{~m}$ and $31.758 \mathrm{~cm}$ respectively. Plot 6 and 2 had the highest and lowest AGB of $84257.16 \mathrm{~kg}$ and $5489.7395 \mathrm{~kg}$ respectively. Analysis of the two parameters showed that plot 6 had an average height of $35.3 \mathrm{~m}$ and an average DBH of $59.0 \mathrm{~cm}$ while plot 2 had an average height of $23.8 \mathrm{~m}$ and an average DBH of $17.7 \mathrm{~cm}$. Accordingly, high values of DBH and height resulted in high estimated above ground biomass.

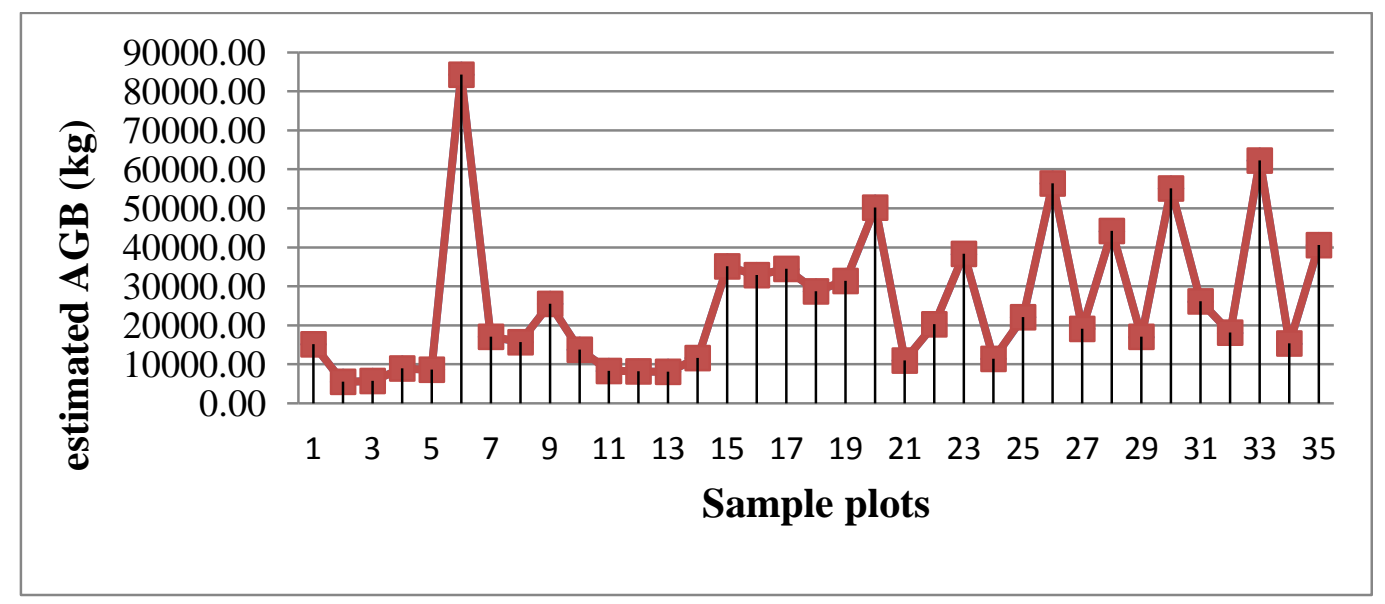

Figure 3. Variation of estimated biomass across the sampled plots 
The variations in the AGB in the different plots is therefore attributed to the differences in the DBH and height parameters. Further analysis was carried out to determine which of the two tree parameters, that is, tree height and DBH contributes more to AGB. The Biomass of 229 trees was used for this analysis and the correlation between DBH and AGB was established to be 0.69 while that of tree height and AGB was 0.46. It therefore implies that DBH contributes more to AGB than tree height.

\subsection{Correlation between AGB and radar backscatter}

The correlation between AGB and radar backscatter for the $\mathrm{HH}$ and $\mathrm{HV}$ polarization was assessed using data from selected 20 sample plots. The backscatter values were plotted against the AGB for each plot as shown in Figures 4 and 5. A goodness of fit was measured and found to be 0.272 and 0.353 for the $\mathrm{HH}$ and $\mathrm{HV}$ polarizations respectively with corresponding pairwise correlation coefficients $(\rho)$ of 0.522 and 0.595. Nguyen (2010) carried a similar analysis in Afram Headwaters Forest in Ghana and found correlation coefficients of 0.305 and 0.691 between AGB and the $\mathrm{HH}$ and $\mathrm{HV}$ polarizations respectively. In each of these cases, the HV-polarized image showed a high potential for estimating AGB. A multilinear coefficient of determination involving both the $\mathrm{HH}$ and $\mathrm{HV}$ polarizations was found to be 0.355 , indicating an improvement of coefficients obtained using single $\mathrm{HH}$ and $\mathrm{HV}$ polarizations. Data of 10 independent plots was used for validation of the model. A pairwise correlation coefficient ( $\rho$ ) of 0.594 and regression coefficient of determination $\left(\mathrm{r}^{2}\right)$ of 0.583 was obtained at $95 \%$ level of significance (see Figure 6).

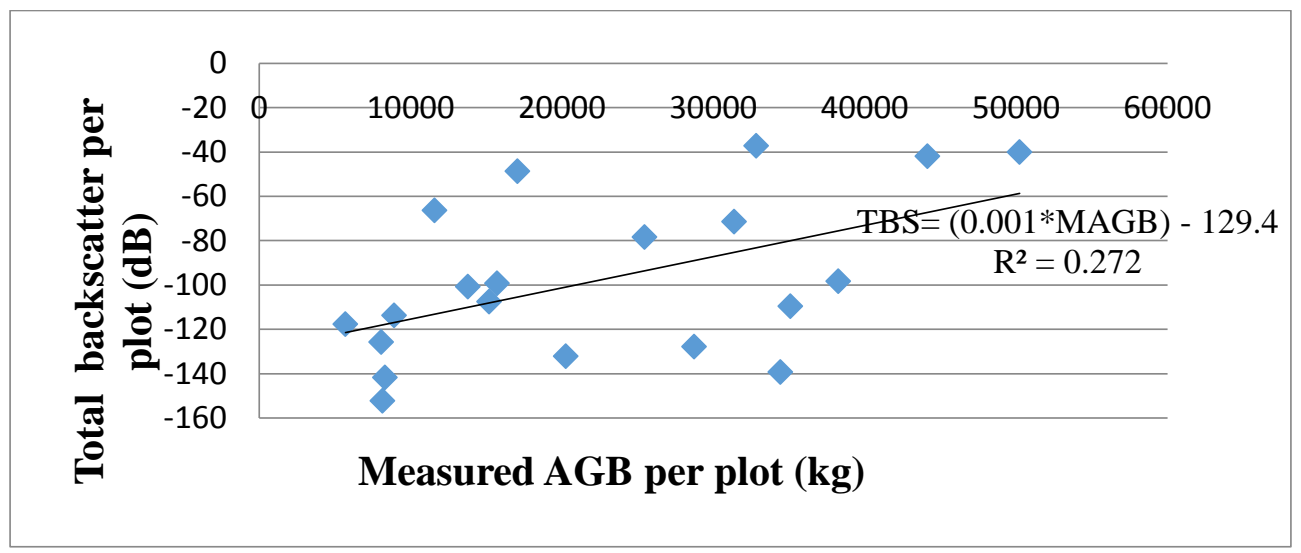

Figure 4. Correlation between the backscatter for the for the $\mathrm{HH}$ polarisation and AGB 


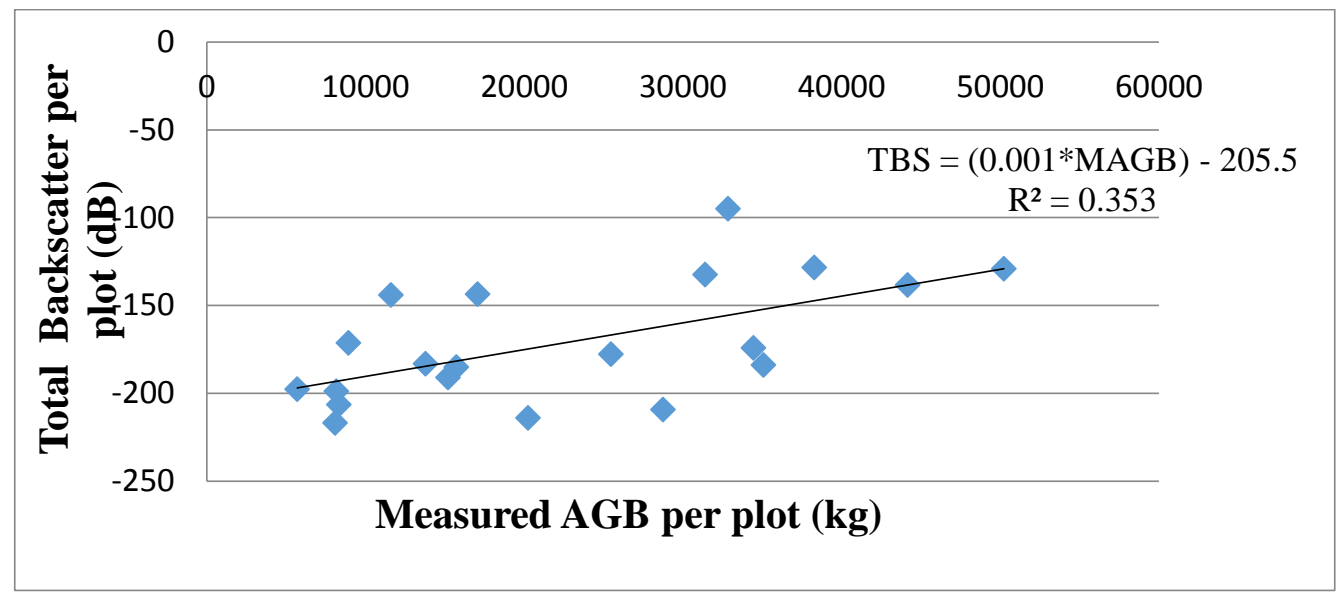

Figure 5. Correlation between backscatter of the HV polarization against AGB

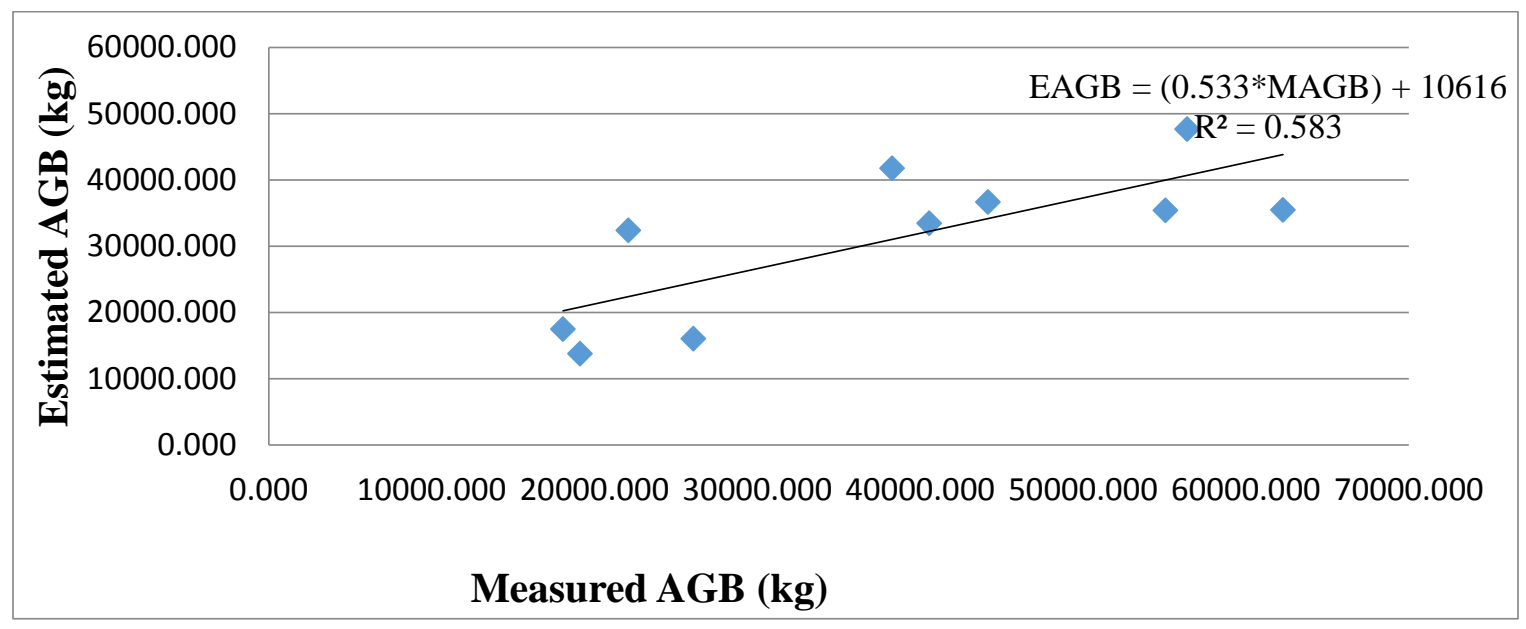

Figure 6. Estimated AGB compared with measured biomass based on multi-linear model

\subsection{Mapping above ground biomass and carbon stocks in Bwindi National Park}

Figure 7 shows the spatially explicit estimated AGB in the BINP. The brown and yellow areas exhibit more AGB per pixel as compared to the green areas. This is attributed to the tall trees with large diameters found in the valleys. In contrast, areas shown as green are those located on the mountain peaks and have low vegetation cover. The available trees are short with small diameters resulting in low estimated biomass values. The resulting biomass $(\mathrm{kg})$ was converted to carbon stocks $(\mathrm{kg})$ based on equation 5 and the corresponding results are shown in Figure 8. 


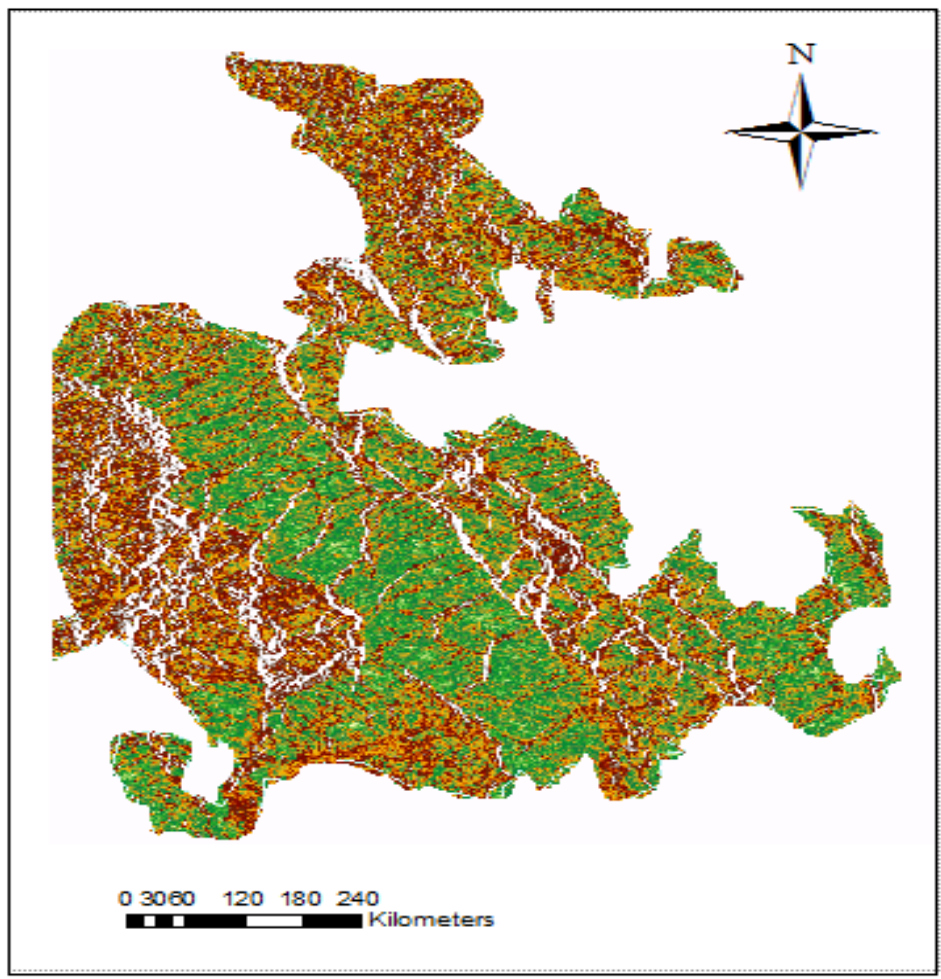

High: 27318

Low: 6347

Figure 7. Estimate Biomass $(\mathrm{Kg})$ in the Bwindi National Park

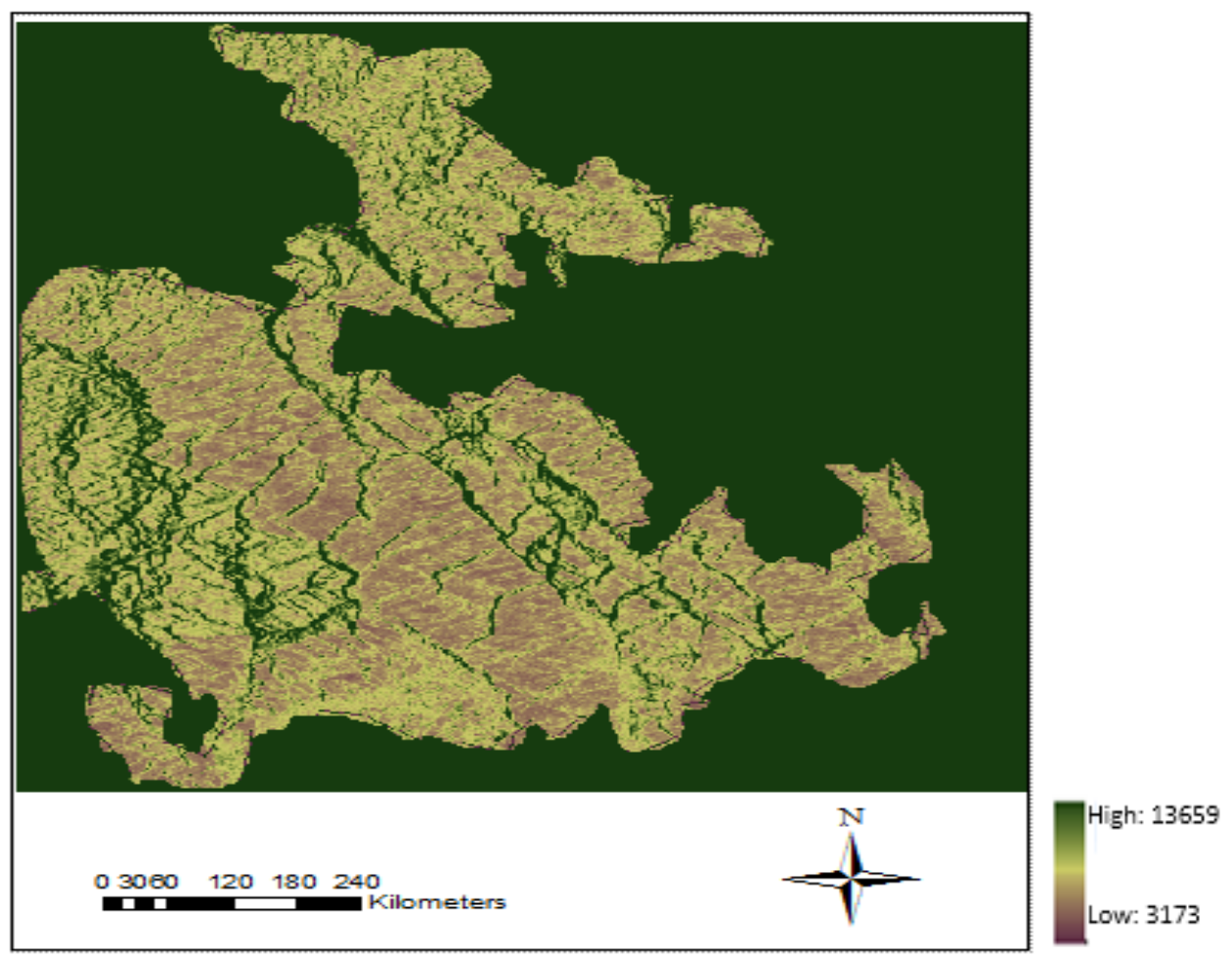

Figure 8. Estimated carbon (in $\mathrm{Kg}$ ) in the Bwindi National Park 


\section{Conclusion and recommendations}

The aim of this study was to assess the potential of two polarizations of ALOS PALSAR data for biomass and carbon estimation in the Bwindi Impenetrable National Park. Field work was carried out to determine tree heights and DBH which were very important variables for biomass and carbon assessment. Linear regression equations were established to relate biomass with tree parameters. Similarly, multiregression equation was formulated for the determination of biomass from the $\mathrm{HH}$ and $\mathrm{HV}$ polarizations. Overall, the cross polarization (HV) showed high potential for biomass and carbon assessment. Layover and shadowing however made estimation of biomass from radar data difficult. These characteristics lead to extraction of wrong pixel values which affect the estimated biomass and carbon values. Furthermore, a time lag of more than 5 years between radar and field data collection may have affected the amount of estimated biomass. It would be desirable to acquire ground truth data and satellite images at approximately the same time. Despite these challenges, the ALOS PALSAR data showed high potential for assessment of biomass and carbon in BINP and similar environments.

\section{Acknowledgements}

The authors would like to thank the European Space Agency (ESA) for providing the ALOS PALSAR data used in the study under project number CIP7583. Our gratitude also goes to the International Foundation for Science (IFS) for funding the project. Finally, we would like to recognize the contribution made by Dan Kazigaba based at the National Forest Research Institute (NAFORI) who helped during the field data collection.

\section{References}

AMADO, A. L. 2012. Biomass/carbon estimation and mapping in subtropical regions of Chitwan, Nepal (2012): A comparison between VHR Geo-Eye satellite images and airborne LiDAR data. Enschede, Netherlands. ANAYA, J. A., CHUVIECO, E. \& PALACIOS-ORUETA, A. 2009. Aboveground biomass assessement in Columbia : A remote sensing approach. Forest Ecology and Management, 257, 1237-1246.

AUSTIN, J. M., MACKEY, B. G. \& VAN NIEL, K. P. 2003. Estimating forest biomass using satellite radar: an explanatory study in a temperature Australian Eucalyptus forest. Forest Ecology and Management, 176, 575-585.

BEAUDOIN, A. L. 1994. Retrieval of forest biomass from SAR data. international Journal of Remote Sensing, 2777-2796.

BROWN, S. 2002. 'Measuring carbon in forests: current status and future challenges'. Environmental pollution, $116,363-372$.

CHAVE, J., ANADAlO, C., BROWN, S., CAIRnS, M., CHAMBER, J., EAMUS, D., FOLSTER, H., FROMARD, F., HIGUCHI, N., KIRA, T., LESCURE, J., P., NELSON, B., OGAWA, H., PUIG, H., RIERA, B. \& YAMAKURA, T. 2005. Tree allometry and improved estimation of carbon stocks and balance in tropical forests. Oecologia, 145, 87-99. 
CLEMENTS, T. 2010. Reduced Expectations: the political and institutional challenges of REDD. Oryx, 44, 309310.

DE JONG, S. M. 2003. Aboveground biomass assessment of mediterranean forests using airborne imaging spectrometry: The DAIS Peyne Experiment. Interrnational Journal of Remote sensing 24, 1505-1520.

FAO 2010. Global forest resource assessment -main report. Rome, Italy.

GONZALEZ, P., ASNER, G. P., BATTlES, J. J., LEFSKY, M. A., WARING, K. M. \& PALACE, M. 2010. Forest carbon densities and uncertainties from Lidar, QuickBird, and field measurements in California. Remote Sensing of Environment, 114, 1561-1575.

HILL, T. C., WILliaMS, M., BLOOM, A. A., MITCHARD, E. T. A. \& RYAN, C. M. 2013. Are Inventory Based and Remotely Sensed Above-Ground Biomass Estimates Consistent? PLoS ONE 8.

ICIMOD, ANSAB \& FECOFUN 2010. Forest on forest carbon stock in Ludikola, kayarhola and Charnawati watersheds in Nepal. Technical review by Terra Global.

KUPLICH, T. M. 2000. JERSIISAR backscatter \& its relationship wit h biomass of regenerating forests. international Journal of Remote Sensing, 21, 2513-2518.

LU, D. 2006. 'The potential and the challenge of remote sensing based biomass estimation'. International Journal of Remote Sensing, 27, 1297-1328.

LUCAS, R., ARMSTON, J., FAIRFAX, R., FENSHAM, R., ACCAD, A., CARREIRAS, J., KELLEY, J., BUNTING, P., CLEWLEY, D., BRAY, S., METCALFE, D., DWYER, J., BOWEN, M., EYRE, T., LAIDLAW, M. \& SHIMADA, M. 2010. Impacts of Surface Moisture Condition and Vegetation Structure. IEEE Journal of Selected Topics in Applied Earth Observations and Remote Sensing, 3, 576-593.

LUCKMAN, A., BAKER, J., TATIANA, M. K., CORINA DA COSTA, F. Y. \& F, A. C. 1997. A study of the relationship between radar backscatter and regenerating tropical forest biomass for space borne SAR instruments. 60, 1-13.

MITCHARD, E. T. A., SAATCHI, S. S., WHITE, L. J. T., ABERNETHY, K. A., JEFFERY, K. J., LEWIS, S. L., COLLINS, M., LEFSKY, M. A., LEAL, M. E., WOODHOUSE, I. H. \& MEIR, P. 2011. Mapping tropical forest biomass with radar and spaceborne LiDAR: overcoming problems of high biomass and persistent cloud. Biogeosciences Discuss., 8, 8781-8815.

MITCHARD, E. T. A., WILLIAMS, M., SAATCHI, S. S., RYAN, C. M., WOODHOUSE, H., LEWIS, S. L., NANGENDO, G., FELDPAUSCH, T. R., RIBEIRO, N. S. \& MEIR, P. 2009. Using satellite radar backscatter to predict above-ground woody biomass: A consistent relationship across four different African landscapes. GEOPHYSICAL RESEARCH LETTERS, 36.

NAISEH, G., MAHMOD, R. S. \& ALI, M. 2010. A review on biomass estimation methods using synthetic aperture radar data International Journal of Geomatics and Geosciences 1, 776-788.

NGUYEN, N. T. 2010. Estimation and mapping of above ground biomass for the assessment and mapping of carbon stocks in tropical forest using SAR data : a case study in Afram headwaters forest, Ghana., University of Twente.

POWELl, S. L., COHEN, W. B., HEALEY, S. P., KENNEDY, R. E., MOISEN, G. G., PIERCE, K. B. \& OHMANN, J. L. 2010. Quantification of live aboveground forest biomass dynamics with Landsat timeseries and field inventory data: A comparison of empirical modeling approaches. Remote Sensing of Environment, 114, 1053-1068.

PULLIAINEN, J. M. 2003. Feasibilit y of mult itemporal interferometric SAR data for standlevel est imation of boreal forest stem volume. Remote Sensing of Environment, 397-409.

RANSON, K. J. \& SUN, G. 1994. Mapping Biomass of a Northem Forest Using Mult ifrequency SAR Data. IEEE Transactions on Geoscience and Remote Sensing, 32, 388-396.

RAUSTE, Y. 2005. Multi-temporal JERS SAR data in boreal forest biomass mapping. Remote Sensing of Environment, 97, 263-275.

SANTOS, J. R. 2003. Airborne Pband SAR applied to the aboveground biomass studies in the Brazilian tropical rainforest. Remote Sensing of Environment, 87, 482-493.

SUN, G. R. 2002. Radiometric slope correction for forest biomass estimation from SAR data in the western Sayani Mountains, Siberia. Remote Sensing of Environment, 79, 279-287.

THENKABAIL, P. S. 2004. Biomass estimations and carbon stock calculations in the oil palm plantations of African derived savannas using IKONOS imagery. Remote Sensing of Environment, 25, 5447-5472. 